Agronomía Costarricense 43(2): 61-73. ISSN:0377-9424 / 2019

www.mag.go.cr/rev_agr/index.html www.cia.ucr.ac.cr

\title{
ETIOLOGÍA DE LAS PUDRICIONES EN EL TALLO DE Hylocereus costaricensis, PROVOCADAS POR Enterobacter hormaechei, EN COSTA RICA
}

\author{
Kenneth Retana-Sánchez ${ }^{1 / *}$, Oscar Castro-Zúñiga**, Mónica Blanco-Meneses ${ }^{* * *}$, \\ Andrea Quesada-González.****
}

Palabras clave: Pudrición marrón; Hylocereus costaricensis; Enterobacter hormaechei.

Keywords: Brown rot; Hylocereus costaricensis; Enterobacter hormaechei.

Recibido: 04/05/18

Aceptado: 05/09/19

RESUMEN

En el 2011 se realizó una investigación para identificar el agente causal de las pudriciones presentes en los tallos de Hylocereus costaricensis en Costa Rica. En época lluviosa, la sintomatología asociada a estas enfermedades correspondió a pequeñas pudriciones amarillentas que por lo general iniciaron del borde del cladodio y se extendieron hacia adentro del mismo, hasta que se descompuso todo el tallo. Durante la época seca, se observaron manchas circulares anaranjadas que posteriormente se tornaron de color marrón oscuro. Para determinar el agente causal se recolectaron 25 muestras de cada tipo de pudrición, cladodios completos con diferentes estados de desarrollo de los síntomas, a partir de las cuales se realizó 15 aislamientos de cada enfermedad. Se obtuvo una bacteria de forma consistente de cada sintomatología, con las cuales se realizó la identificación, caracterización basada en pruebas bioquímicas e identificación molecular, así como la verificación de los postulados

1 Autor para correspondencia. Correo electrónico: kretana@uned.ac.cr

* Universidad Estatal a Distancia, Cátedra de Ciencias Agropecuarias, Costa Rica. (DD 0000-0003-1937-7249.

** Universidad de Costa Rica, Facultad de Ciencias Agroalimentarias, Centro de Investigaciones en Protección de Cultivos, Costa Rica.

(iD) 0000-0002-5999-5749.

\section{ABSTRACT}

Etiology of stem rot on Hylocereus spp. cause by Enterobacter hormaechei in Costa Rica. In 2011 infected samples were examined to identify the causal agent of stem rot of Hylocereus costaricensis in Costa Rica. During the rainy season, symptoms associated with the disease included a small yellowish rot that typically started from the edge of the cladodium and extended inward towards the stem. Eventually the whole stem decayed. During the dry season, orange circular spots appeared on the stem, turning dark brown. For determine the causal agent, were collected 25 samples of each type of decay, complete cladodes with different stages of symptom development, from which 15 isolations of each disease were made. A bacterium was obtained consistently from each symptomatology, with which the identification, characterization based on biochemical tests and molecular identification was carried out, as well as the verification of Koch's postulates. Results

\footnotetext{
*** Universidad de Costa Rica, Facultad de Ciencias Agroalimentarias, Centro de Investigaciones en Protección de Cultivos Costa Rica.

(D) 0000-0003-2642-3899.

**** Tecnológico de Costa Rica, Escuela de Química, Costa Rica. (D) 0000-0003-0163-6775.
} 
de Koch. De acuerdo con los resultados de las pruebas realizadas, los síntomas fueron provocados por una misma bacteria. Con base en el análisis molecular, secuenciación de la región 16S, la bacteria presentó un 99,2\% de similitud con Enterobacter hormaechei (KJ999997). Según los resultados de las pruebas de verificación de los postulados de Koch, se obtuvo un 100\% de infección y una sintomatología similar a la observada en campo, así como el mismo organismo inoculado. Este es el primer reporte de esta bacteria como patógeno de los tallos de Hylocereus costaricensis en el continente americano.

\section{INTRODUCCIÓN}

La pitahaya (Hylocereus spp.) es un cactus epífito con una creciente importancia comercial a nivel internacional, debido a su potencial como planta ornamental y para el consumo de tallos y frutos. La industrialización del cultivo ha favorecido la creación de empleos, el aprovechamiento de áreas degradadas y un aumento en los ingresos de pequeños productores (Ortiz y Carrillo 2012, Valencia et al. 2013).

En las últimas décadas el interés por este cultivo se ha incrementado, ya que el fruto contiene pigmentos nitrogenados solubles en agua, llamados betalaínas. Estas presentan potencial como colorantes naturales, debido a que su ámbito de color que va del rojo-violeta al amarillo, se mantienen estables en un ámbito de $\mathrm{pH}$ más amplio (3-7) en comparación con otros colorantes naturales como las antocianinas (Stintzing et al. 2001, Stintzing et al. 2002, Strack et al. 2003, Wybraniec et al. 2001).

En relación con la expansión de la pitahaya en Costa Rica, esta ha tenido un incremento en los últimos años, sin embargo, aún se considera un cultivo minoritario, por lo que no se han realizado estudios detallados sobre las enfermedades que puede presentar. A nivel mundial se reporta que este cactus puede ser indicated that the symptoms were caused by the same bacteria. Based on sequencing of the $16 \mathrm{~S}$ region, the bacterium showed $99.2 \%$ similarity with Enterobacter hormaechei (KJ999997). According to Koch's postulates, a similar symptomatology was obtained on plants from the field and on inoculated plants. This is the first report of this pathogen causing damage to the stem of Hylocereus costarricensis in American continent.

atacado en tallos y frutos por las bacterias Enterobacter cloacae, Erwinia carotovora y Xanthomonas campestris, y algunos hongos como Fusarium oxysporum, Fusicoccum sp., Curvularia lunata, Colletotrichum gloesporioides y Neoscytalidium dimidiatum (Valencia et al. 2004, Wright et al. 2007, Palmateer y Ploetz 2007, Masyahit et al. 2009, Masratul et al. 2013).

En plantaciones comerciales de este cactus en México, se reportó la presencia en los tallos de una pudrición suave. Se identificó una enterobacteria como agente causal de dicho síntoma (Valencia et al. 2003).

Debido a la heterogeneidad de las especies del género Enterobacter y a la cercanía que presentan en las secuencias de la región 16S, es compleja la identificación de las mismas. La mayoría de las especies que muestran una relación genética por encima de un $60 \%$, con E. cloacae, son agrupadas en el complejo Enterobacter cloacae (Hoffmann y Roggenkamp 2003).

Con base en lo anterior y ante la problemática fitosanitaria que se presenta en este cultivo en el país, se planteó como objetivo de este trabajo el aislamiento, identificación y la verificación de los postulados de Koch de la bacteria que causan las pudriciones que afectan los tallos de la pitahaya en Costa Rica. 


\section{MATERIALES Y MÉTODOS}

\section{Recolección de muestras}

La investigación se realizó en la finca "El Brillante", la cual se dedica a la producción de pitahaya orgánica y se ubica en Miramar de Puntarenas $\left(10^{\circ}\right.$ latitud norte y $84^{\circ}$ longitud oeste), Costa Rica. La población en el área de estudio fue de 2666 plantas.ha $^{-1}$, de las cuales se seleccionó 992 plantas distribuidas en 38 hileras para realizar esta investigación.

En la plantación se presentaron 2 tipos de pudrición con sintomatologías distintas, una se presentó en época seca y la otra en el periodo lluvioso. De cada una estas se tomaron 25 muestras, cladodios completos con diferentes estados de desarrollo de la enfermedad; cada una se envolvió en papel periódico humedecido y fue colocada en una bolsa plástica. El material recolectado fue llevado al Laboratorio de Fitopatología del Centro de Investigación en Protección de Cultivos (CIPROC) de la Universidad de Costa Rica (UCR).

Se evaluó la evolución de los síntomas presentes en el campo durante un año. Para cada tipo de pudrición se marcaron 30 plantas a lo largo de la plantación con diferentes estados de desarrollo de los síntomas y se procedió a evaluar cambios visibles mediante fotografías generadas cada 15 días durante el periodo antes mencionado.

\section{Caracterización de síntomas y aislamiento del agente causal}

Para cada tipo de pudrición, se realizó la descripción de los síntomas presentes en las 25 muestras recolectadas, con base en las características visuales que cada una presentó, con ayuda de un estereoscopio. Los aspectos que se evaluaron fueron el color, tamaño y textura de lesiones, además, la consistencia y la tonalidad del tejido interno.

Se seleccionaron 15 cladodios sintomáticos de cada enfermedad, a partir de los cuales se llevó a cabo el aislamiento del agente causal mediante la metodología descrita por French y
Hebert (1980) para hongos y bacterias. La desinfección del material se realizó con etanol al 70\% e hipoclorito de sodio al $1 \%$ durante $50 \mathrm{~s}$ y $20 \mathrm{~s}$, respectivamente.

Los medios de cultivo utilizados fueron MacConkey y Agar-Triptona-Soya (ATS) (Atlas 2010). En cada uno de los síntomas, se rasgó el tejido de manera longitudinal y se extrajeron segmentos de la zona de avance en la parte interna del mismo (parte enferma y parte sana). Se triplicó cada aislamiento por cada medio utilizado, para un total de 45 repeticiones, por cada tipo de pudrición. Estos se incubaron en una cámara oscura a temperatura de $30^{\circ} \mathrm{C}$, por un periodo de 3 días.

Una vez transcurrido este tiempo, se obtuvo una colonia bacteriana por cada tipo de pudrición, visualmente distintas, que predominaron en todos los aislamientos realizados. Con ambas bacterias, se procedió a realizar la separación, con un asa desinfectada, de colonias individuales en medio ATS. Dichas colonias se incubaron bajo las mismas condiciones de temperatura y oscuridad, antes descritas, por un periodo de 24 horas.

A partir de una colonia individual de cada bacteria, se realizó la purificación y multiplicación de estas en medio ATS. Se contó con 3 repeticiones por bacteria y se incubaron a $30^{\circ} \mathrm{C}$ por 24 horas.

Con el material purificado, se procedió a realizar las siguientes pruebas bioquímicas y moleculares para la identificación:

\section{Tinción de Gram}

Se realizó la prueba de tinción de Gram con el objetivo de confirmar y determinar la morfología de las bacterias. Lo anterior se llevó a cabo mediante la metodología descrita por Schaad et al. (2001). Se observó la morfología de estas en el microscopio de luz, con un aumento de 100X.

\section{Prueba Triple Azúcar-Hierro (TSI)}

Cada bacteria se inoculó por duplicado con aguja bacteriológica estéril en tubos de ensayo 
que contenían aproximadamente $10 \mathrm{ml}$ de medio TSI y se incubaron por 24 horas a $30^{\circ} \mathrm{C}$. Transcurrido este periodo, se evaluó el perfil de fermentación que presentaban, según el cambio de color por el indicador de $\mathrm{pH}$ (Rodríguez et al. 2005).

\section{Prueba de las enzimas oxidasa y catalasa}

Se determinó la presencia de la enzima citocromo $\mathrm{C}$ oxidasa en las bacterias en estudio. A partir de una suspensión de cada una de estas, se tomó una gota y se colocó en papel filtro que contenía el reactivo tetrametil-p-fenilendiamina. Se observó la velocidad con que ocurrió el viraje.

En el caso de la prueba de la enzima catalasa, se colocó una gota de cada suspensión bacteriana en un portaobjetos y se le agregó peróxido de hidrógeno $15 \%\left(\mathrm{H}_{2} \mathrm{O}_{2}\right)$. Se evaluó la liberación de oxígeno mediante la formación de burbujas (Rodríguez et al. 2005).

\section{Identificación molecular}

\section{Extracción del ácido desoxirribonucleico $(A D N)$}

Se realizó la identificación molecular en el Laboratorio de Técnicas Moleculares Aplicadas a la Fitoprotección del CIPROC, UCR, para lo cual se extrajo ADN a partir de 2 repeticiones de cada bacteria purificada, con 24 horas de crecimiento, mediante el uso del método CTAB (Murray y Thompson 1985). El ADN fue cuantificado con un espectofotómetro y se llevó a una concentración final de $80 \mathrm{ng} . \mu \mathrm{L}^{-1}$.

\section{Reacción en Cadena de la Polimerasa (PCR) y secuenciación del ADN}

La reacción en cadena de la polimerasa (PCR) se realizó con los cebadores específicos: 16S, 27F (5'- AGAGTTTGATCMTGGCTCAG-3’) y 1492R (5'-TACGGYTACCTTGTTACGACTT-3') descritos por Lane et al. (1985), que amplifican la secuencia total del ARN del gen ribosomal $16 \mathrm{~S}$.
Para cada repetición, la reacción se llevó a cabo en un volumen final de $25 \mu \mathrm{L}$, que consistió en $15,25 \mu \mathrm{L}$ de agua desionizada ultrapura, 2,5 $\mu \mathrm{L}$ de buffer 10X (1X), 2,5 $\mu \mathrm{L}$ de dNTPs $(1 \mathrm{mM})$, $1,25 \mu \mathrm{L}$ de cada cebador $(0,5 \mu \mathrm{M})$ y $0,25 \mu \mathrm{L}$ de DreamTaq DNA Polymerase ( 1 U. $\left.\mu \mathrm{L}^{-1}\right)$. Se utilizó un control negativo, el cual fue una reacción sin ADN. La reacción de amplificación se llevó a cabo mediante el siguiente perfil térmico: predesnaturalización inicial a $96^{\circ} \mathrm{C}$ durante 2 minutos, seguido por 35 ciclos de desnaturalización a $96^{\circ} \mathrm{C}$ durante un minuto, anillamiento a $56^{\circ} \mathrm{C}$ por un minuto, extensión a $72^{\circ} \mathrm{C}$ por 2 minutos, seguidos de una extensión final a $72^{\circ} \mathrm{C}$ durante 10 minutos.

El producto de PCR (aproximadamente de 1500 pares de bases), de cada repetición por bacteria, para $16 \mathrm{~S}$ se confirmó mediante electroforesis en gel de agarosa $(0,8 \%)$, que se comparó con un marcador de peso molecular de $100 \mathrm{pb}$, GeneRuler. El producto de PCR se digirió con una endonucleasa llamada Exonuclease I y se llevó a una concentración de $50 \mathrm{ng}$. $\mu \mathrm{L}^{-1}$. Posteriormente, los 4 productos de PCR obtenidos se enviaron a secuenciar a la empresa Macrogen Inc., Corea del Sur. Se obtuvieron secuencias en ambas direcciones para cada muestra generada a partir de ciclos fluorescentes con un secuenciador.

\section{Alineamiento de las secuencias y análisis filogenéticos}

La calidad de las secuencias se confirmó con un alineamiento bidireccional y por comparación con los cromatogramas con el programa BioEdit (Hall 1999); además, se cortaron las terminaciones 5' y 3' de las cadenas para facilitar el alineamiento. Se utilizó la herramienta informática Blast (Basic Local Alignment Search Tool del National Center for Biotechnology Information (NCBI), a partir de la cual se comparó la secuencia generada frente a las secuencias que se encuentran en la base de datos del banco de genes (GenBank).

El análisis filogenético se realizó con el software MEGA 6. Se llevaron a cabo las pruebas del Vecino más cercano y Máxima Verosimilidad, 
con 1500 repeticiones y accesiones de Enterobacter spp., provenientes del Genbank.

\section{Prueba Vitek 2}

Como respaldo, se llevó a cabo la identificación de las bacterias mediante el sistema automatizado de identificación Vitek 2, en el Laboratorio de Bacteriología Médica de la Facultad de Microbiología de la UCR. Se realizaron 2 repeticiones por bacteria. El sistema Vitek 2 es una prueba bioquímica que utiliza una tarjeta con 64 pozos, cada uno de los cuales contiene un sustrato diferente con los que se miden las actividades bioquímicas de las bacterias, tales como acidificación, alcalinización, hidrólisis enzimática y crecimiento en presencia de sustancias inhibitorias (Pincus 2005).

\section{Identificación de organismos secundarios}

En época seca, sobre algunas de las lesiones viejas provocadas por la bacteria, se presentaron estructuras redondeadas y oscurecidas, por lo que se realizó el aislamiento de tejido con estos signos en cajas Petri con medios de cultivo agar-papa-dextrosa (PDA) y V8 (Atlas 2010). Se contó con 2 repeticiones por medio de cultivo y se colocaron en oscuridad y a $25-30^{\circ} \mathrm{C}$ por 5 días.

Se observaron los conidios de los organismos obtenidos, en el microscopio de luz, con un aumento de 100X. Asimismo, se visualizaron las estructuras oscurecidas con el estereoscopio.

\section{Verificación de los postulados de Koch}

A partir de cada una de las bacterias purificadas, se preparó una suspensión de aproximadamente $1,0 \times 10^{8}$ unidades formadoras de colonias por mililitro (UFC.ml-1) y se inocularon en tallos sanos de pitahaya. Para esto se tomaron $20 \mathrm{ml}$ de agua estéril y se les agregó pequeñas cantidades de bacteria hasta lograr una turbidez similar a un tubo de McFarland con la concentración mencionada.
La inoculación se llevó a cabo en el invernadero del Laboratorio de Fitopatología de la Universidad de Costa Rica en época seca (Febrero, 2014). En cladodios sanos y previamente desinfectados con etanol al $70 \%$ se inyectó las suspensiones preparadas. Para cada bacteria se inocularon 40 puntos distribuidos en 4 cladodios a los cuales se les colocó $0,5 \mathrm{ml}$ de suspensión por cada punto de infección. Se contó con un testigo en cada cladodio que consistió en inyectar en la cara opuesta de los puntos de infección agua estéril con el mismo volumen y con la cantidad de puntos antes mencionados.

Se confirmaron los postulados de Koch gracias al reaislamiento de las bacterias inoculadas mediante el protocolo descrito por French y Hebert (1980) en los medios de cultivo antes mencionados, con 3 repeticiones. La identificación del organismo obtenido se realizó por medio de las mismas pruebas bioquímicas implementadas anteriormente.

\section{RESULTADOS Y DISCUSIÓN}

En la plantación se presentaron síntomas diversos asociados al patógeno en estudio. Conforme la enfermedad evolucionó en el tiempo, se dieron cambios en la coloración y morfología de las lesiones provocadas por la bacteria.

De acuerdo con las evaluaciones realizadas, en el área de estudio se presentaron 2 tipos de pudriciones, una durante la época lluviosa y otra durante la época seca.

\section{Época lluviosa}

Durante la época lluviosa se presentan pudriciones amarillentas en diferentes estados de desarrollo que principalmente inician de los bordes y se extienden hacia el centro del cladodio (Figura 1A, B y C). En algunos casos, las infecciones inician del centro del tallo a partir de lesiones provocadas por otros patógenos, como $N$. dimidiatum, o daños por insectos. 

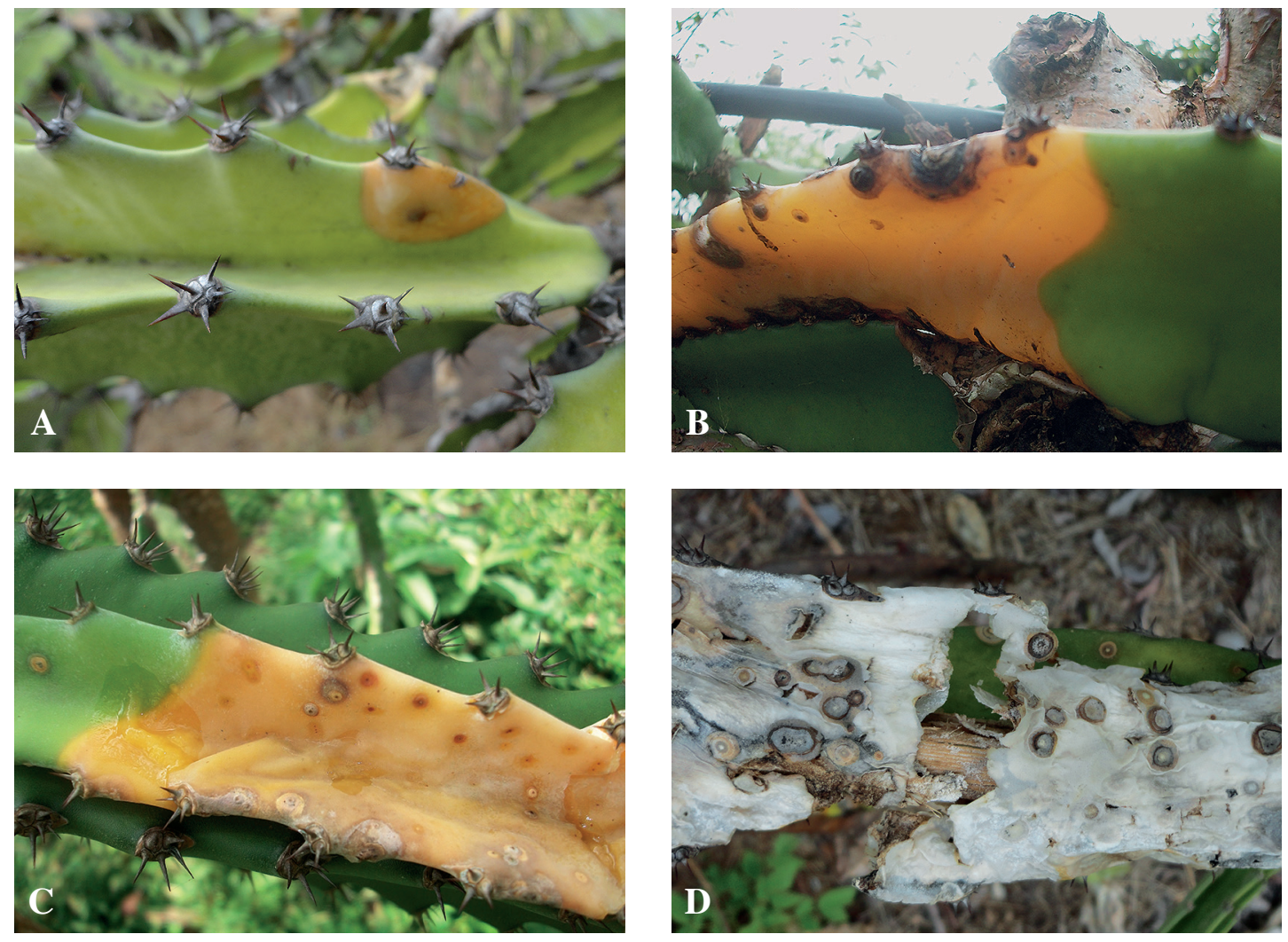

Fig. 1. Síntomas de pudrición presentes en los cladodios de pitahaya durante la época lluviosa. A. Síntoma inicial de la enfermedad. B y C. Avance de la pudrición en el tejido. D. Síntoma final de la pudrición.

En estados avanzados de la enfermedad se presentan 2 situaciones: la pudrición se limita a segmentos del cladodio o se da la pudrición por completo del mismo. En el primer caso el daño es detenido por la planta, debido a que aparentemente esta tiene una alta respuesta hipersensible, la cual se puede generar por los altos contenidos de calcio que la planta es capaz de almacenar en forma de oxalato, tanto en los idioblastos como fuera de estos (Franceschi y Horner 1980, Webb 1999, Faheed et al. 2012). En el segundo caso, el tejido se rompe por el peso del material descompuesto, el cual al caer al suelo deja la epidermis unida al resto de la planta. Esta al secarse presenta una textura suave y papelosa de color blanquecino, lo que facilita su desprendimiento y deja expuesto el haz vascular del tallo afectado (Figura 1D).

Un síntoma similar, provocado por Erwinia carotovora, se reportó en tallos de Hylocereus sp. Según OIRSA (2000), este patógeno se presenta en plantaciones comerciales de pitahaya en Nicaragua y provoca manchas amarillas que posteriormente avanzan como pudriciones acuosas y fétidas que destruyen por completo los cladodios. Cabe señalar que no se menciona la metodología utilizada para la identificación de este patógeno.

\section{Época seca}

Al final de la época lluviosa se presentó una serie de pudriciones de color marrón-negro. 
Estas inician como puntos rojizos sin halo que posteriormente crecen y se tornan de color marrón. Los síntomas se desarrollan tanto en los
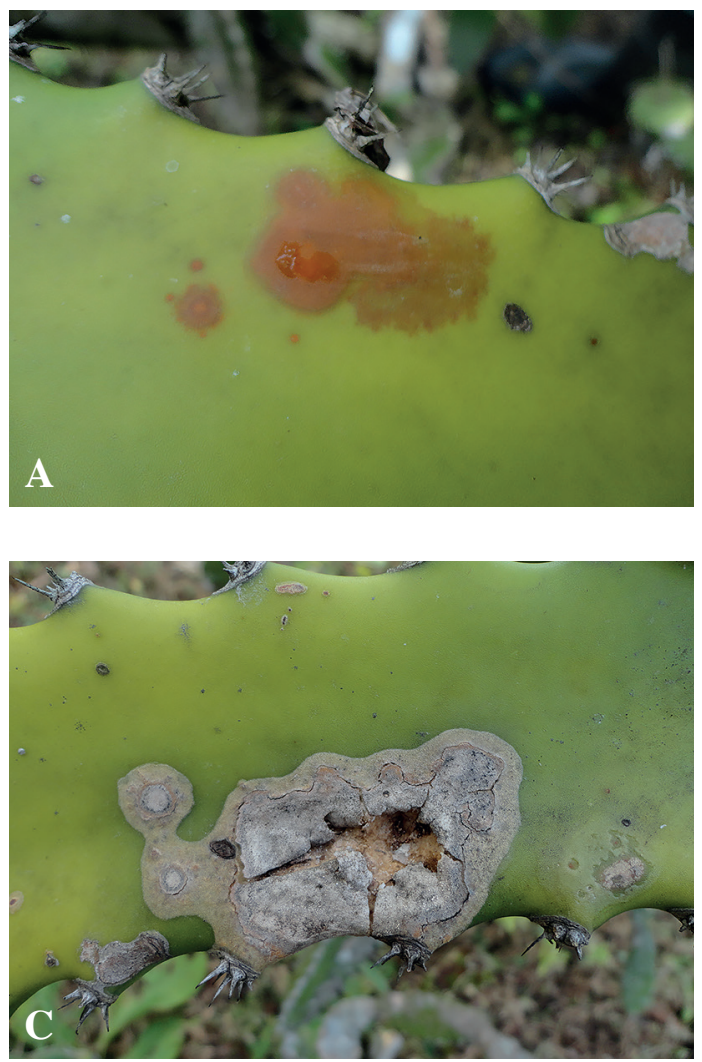

bordes como en el centro del cladodio, con un crecimiento irregular que se extiende por todo el tallo (Figura 2A y 2B).
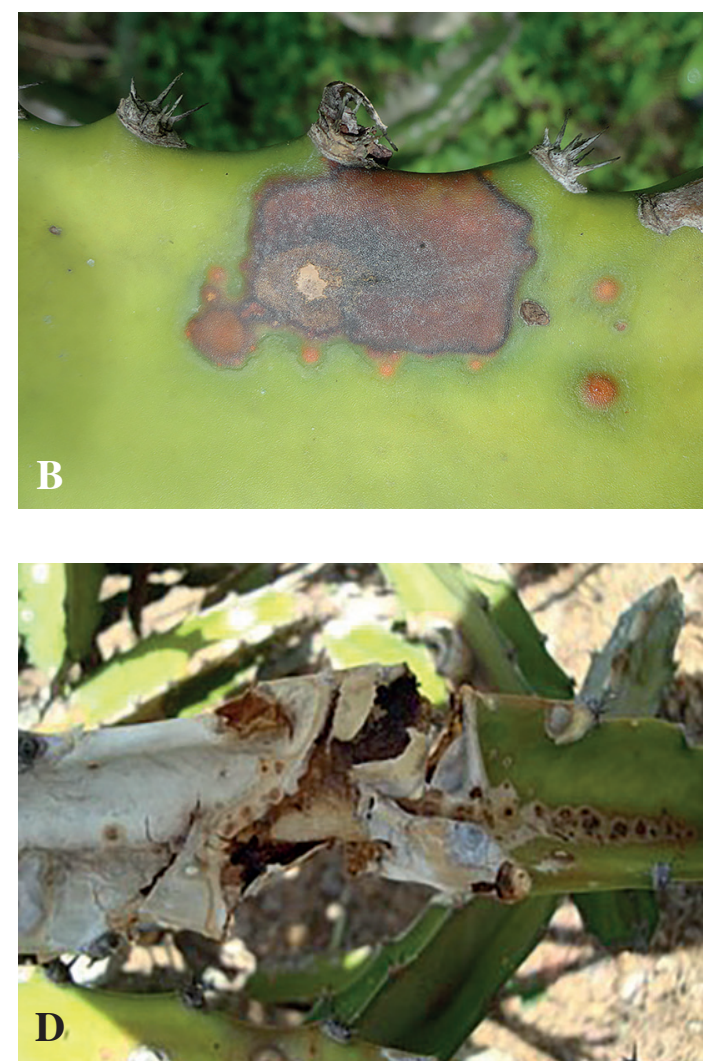

Fig. 2. Síntomas de pudrición presentes en los tallos de pitahaya durante la época seca. A. Síntoma inicial de la enfermedad. B. Avance de la pudrición en el tejido. C. Síntoma final cuando la enfermedad afecta un segmento del tallo. D. Síntoma final cuando la enfermedad afecta todo el cladodio.

Los estados avanzados de la pudrición se presentaron de 2 maneras: si el daño se restringe a un segmento del cladodio, el tejido se contrae y adquiere una coloración blanquecina-grisácea con un halo ligeramente amarillento alrededor de la lesión (Figura 2C). En el caso de que la pudrición afecte completamente el cladodio, el tejido se contrae hacia el haz vascular con una textura acartonada y endurecida de color blanquecino (Figura 2D).
En algunos casos, se da la colonización de estructuras subglobosas de color negro sobre lesiones secas provocadas por la bacteria (Figura 3A). Estas corresponde a acérvulos de Colletotrichum spp. (Figura 3B). También se pueden presentar conidios de Fusarium spp. (Figura 3C). En ambos casos, estos hongos actúan como organismos saprófitos del tejido afectado por $E$. hormaechei. 

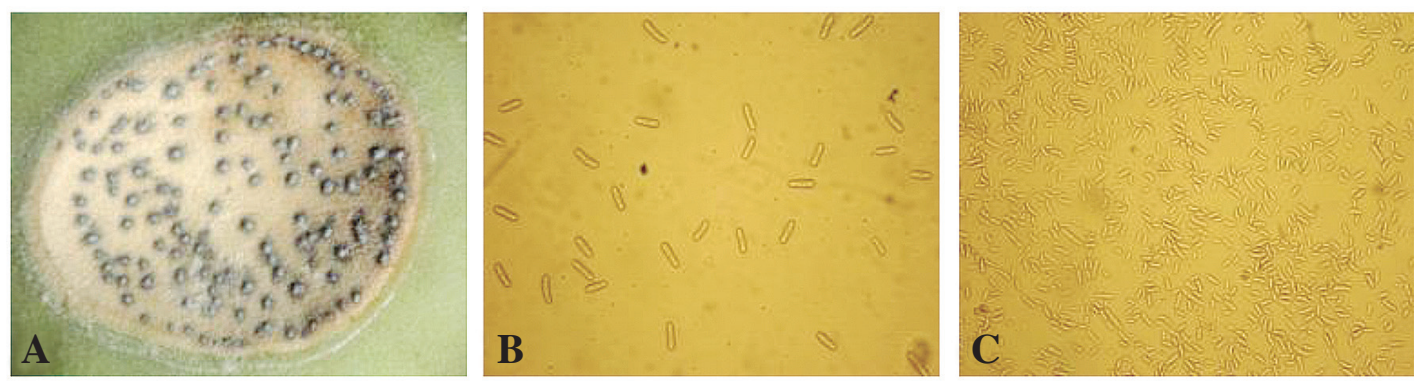

Fig. 3. Organismos saprófitos presentes en lesiones viejas provocadas por E. hormaechei, bajo condiciones de época seca. A. Acérvulos de Colletotrichum spp. B. Conidios de Colletotrichum spp. C. Conidios de Fusarium spp.

Los síntomas descritos concuerdan con lo reportado por Masyahit et al. (2009), que mencionan a Enterobacter cloacae como agente causal de las pudriciones acuosas en plantas de pitahaya en Malasia, las cuales inician como un ablandamiento del tejido, se tornan de color marrón y finalizan con la caída del tejido, sin que se afecte el haz vascular.

De acuerdo con Valencia et al. (2004), en plantaciones comerciales de fruta dragón en México, se desarrolla una pudrición blanda que algunas veces presenta un halo clorótico, y mencionan una enterobacteria (sin identificar) asociada a estos síntomas.

\section{Aislamiento del agente causal}

De cada tipo de pudrición se obtuvo una bacteria de color amarillento en medio de cultivo ATS y de color morado en MacConkey. Con base en lo anterior, se determinó que estas bacterias presentan la capacidad de fermentar lactosa.

\section{Pruebas Gram, Triple Azúcar-Hierro (TSI) y de las enzimas oxidasa y catalasa}

Según los resultados de la tinción de Gram y de las pruebas bioquímicas, ambas bacterias son bacilos (con forma de bastón) Gram negativos, catalasa positivas y oxidasa negativas. Con la prueba con TSI se comprobó que las bacterias fermentan glucosa y sacarosa (A/A). Asimismo, debido a que hubo producción de gas, también presentan la capacidad de fermentar carbohidratos $(\mathrm{G})$.
Lo anterior concuerda con las características que presentan las bacterias que pertenecen a la familia Enterobacteriaceae y al género Enterobacter. Estos agrupan microorganismos con forma de bastón (no pigmentados), aerobios, móviles capaces de fermentar glucosa a ácido con producción de gas o sin ella, son oxidasa negativas y catalasa positivas (Brenner et al. 1986, Puerta y Mateos 2010).

\section{Prueba Vitek 2}

Según los resultados del Vitek 2, la especie de la bacteria corresponde a Enterobacter cloacae spp. cloacae, bionúmero 2627634553533010. E. cloacae y E. hormachechei presentan un $63 \%$ de cercanía filogenética y difieren en que esta última muestra resultados negativos en las pruebas con D-sorbitol, melibiosa, esculina, D-rafinosa, $\alpha$-metil-D-galactosida y adonitol. Se reportan cepas de E. hormachechei que dan positivo en la pruebas con $\mathrm{D}$-sorbitol y melibiosa, lo que sugiere la existencia de biotipos de esta especie (O’Hara et al. 1989, Davin et al. 1997). Lo anterior podría explicar la diferencia obtenida en la identificación de la especie entre esta prueba y el análisis molecular.

\section{Identificación molecular}

Con base en los resultados del Blast, 3 de las 4 secuencias obtenidas corresponden a un mismo organismo. De acuerdo con la región 
16S y la comparación de complementariedad de secuencias de bases según el GenBank, con un total de 1352 nucleótidos analizados, esta bacteria presenta un 99,23\% de homología con Enterobacter hormaechei (número de accesión JF690889.1) y 99,08\% con E. asburiae (número de accesión JQ682630.1). De las secuencias provenientes de los aislamientos analizados, se introdujo una en el Genbank bajo el número de accesión KJ999997.
Cabe señalar que las 3 secuencias provenientes de $H$. costaricensis se unen en único clado, a pesar de algunas mutaciones que las diferencian entre los nucleótidos 373 al 395. Al comparar con otras secuencias provenientes del GenBank, las obtenidas en esta investigación presentan mayor cercanía con $E$. hormaechei y $E$. asburiae, y tienen cierta lejanía con la especie $E$. cloacae (Figura 4).

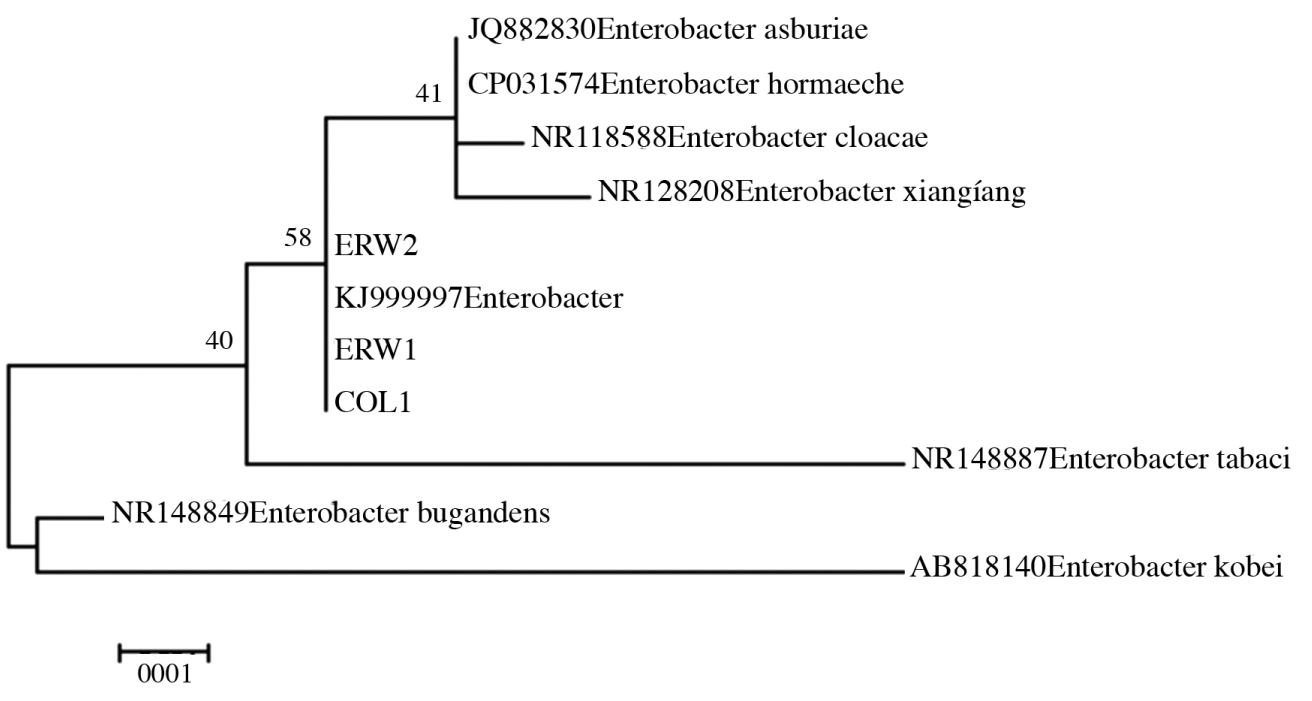

Fig. 4. Relación filogenética entre las secuencias de bacterias obtenidas de H. costaricensis con otras especies cercanas del género Enterobacter.

A pesar de lo anterior, E. hormaechei pertenece al complejo "Enterobacter cloacae", en el cual se incluyen 6 especies: Enterobacter asburiae, Enterobacter cloacae, Enterobacter hormaechei, Enterobacter kobei, Enterobacter ludwigii y Enterobacter nimipressuralis. Estas pertenecen a linajes distintos dentro de un grupo genético común, debido a que presentan relaciones entre sus ADN muy estrechas, es decir, que existen regiones conservadas que se comparten a nivel de género e incluso entre diferentes especies. Fenotípicamente se pueden distinguir mediante pruebas bioquímicas, tales como Biolog, Vitek, TSI, entre otros (O'Hara et al. 1989, Brenner et al. 1986, Hoffmann et al. 2005).

Las bacterias mencionadas comparten regiones conservadas en el genoma que las hace cercanas entre sí, pero presentan polimorfismos que permiten diferenciarlas. E. hormaechei se diferencia de otras enterobacterias porque presenta una fuerte actividad de la enzima glucosa deshidrogenasa. Esta oxida D-glucosa a D-gluconato sin la presencia de pirroquinolina quinona (Grimont y Grimont 2006). 
Cabe mencionar que la identificación molecular de la bacteria se llevó a cabo mediante el estudio del ARNr 16S, porque son fragmentos del genoma altamente repetidos que se han mantenido bastante uniformes a lo largo de la evolución. Además, proporcionan un sitio de iniciación adecuado para la elongación de los imprimadores y así, de forma más fácil, realizar la secuenciación (Lane et al. 1985, Neefs et al. 1993).

Las secuencias de ADN ribosómico (ADNr) de E. cloacae presentan variaciones en la región $16 \mathrm{~S}$ que no permiten formar un grupo taxonómico homogéneo, pero a partir de estas se puede formar un árbol filogenético irregular en el que las cepas de Enterobacter cloacae se interrelacionan fuertemente con otras especies de este género, como E. aerogenes y otras enterobacterias como E. coli. Esto refleja la heterogenicidad genética de las especies, lo que dificulta su identificación sistemática (Tang et al. 1998, Hoffmann y Roggenkamp 2003).

\section{Verificación de los postulados de Koch}

Se obtuvo con un $100 \%$ de infección en cada uno de los cladodios inoculados con la bacteria obtenida (Enterobacter hormaechei). Esta al ser inoculada en tallos sanos, generó los mismos síntomas que se observaron durante la época seca en la plantación. En el testigo se dio la cicatrización de las heridas provocadas con la aguja a partir del octavo día después de iniciadas las inoculaciones, sin que se presentaran síntomas.

Ocho días después de la inoculación (ddi) se observaron manchas amarillentas en los puntos donde se inyectó el patógeno (Figura 5A). La coloración de estas se intensificó y el centro de las mismas se tornó rojizo-marrón a los 12 ddi (Figura 5B). Ocho días después, el tejido infectado se hundió levemente y adquirió una coloración anaranjada con el borde rojizo (Figura 5C).
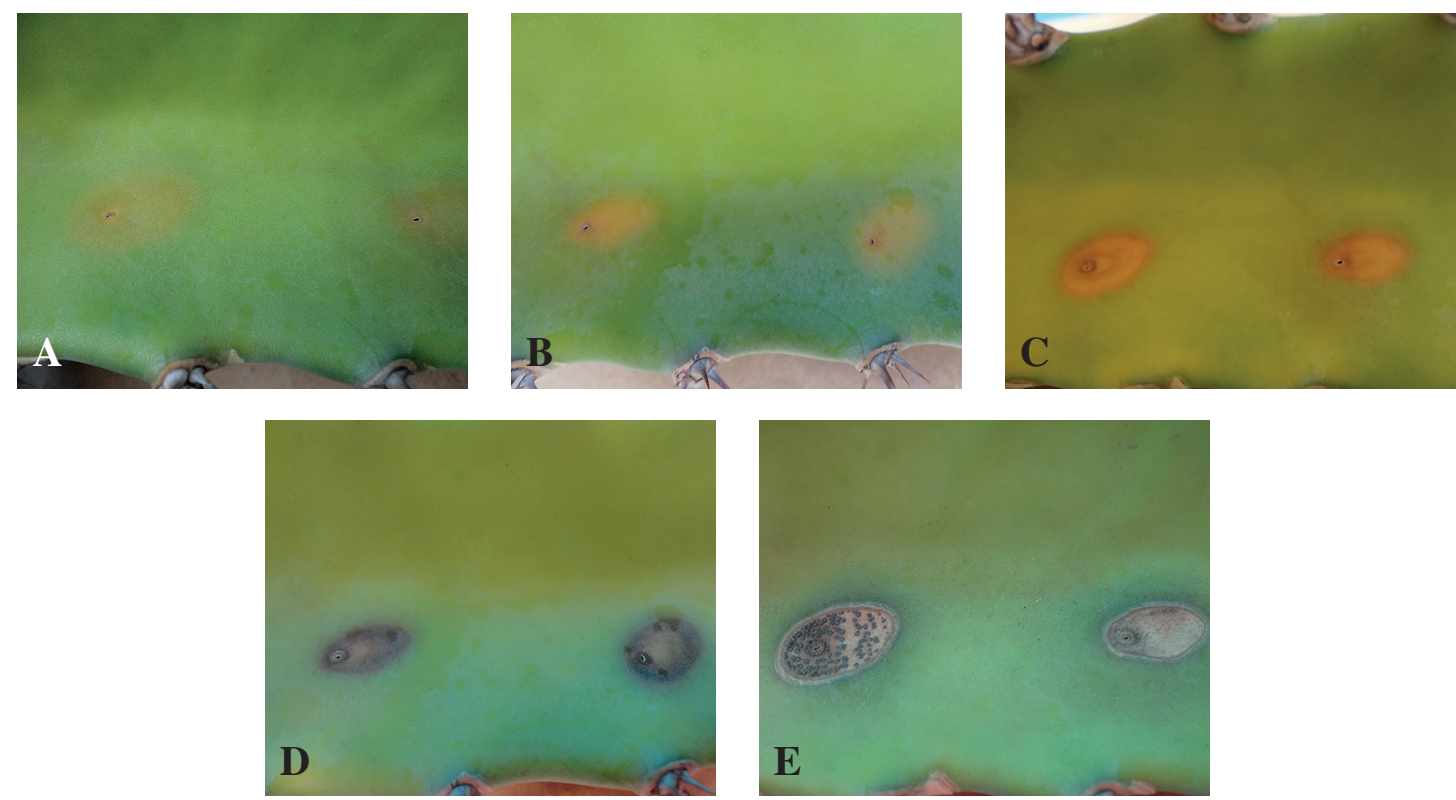

Fig. 5. Resultados de la inoculación de E. hormaechei en tallos sanos. A. Día 8. B. Día 12. C. Día 20. D. Día 24. E. Día 52; después de inoculación. 
A los 24 ddi se dio la pudrición por completo del tejido inoculado (Figura 5D). La fase final de los síntomas se manifestó a los 52 ddi como lesiones blanquecinas con un borde definido color crema y con puntos necrosados en el centro de las mismas (conidios de Colletotrichum spp.) (Figura 5E).

Paralelo a lo anterior, en la cara inmediata a los puntos de infección, se desarrolló una sintomatología similar a la mencionada, pero con mayor vigor. A los 8 días después de la inoculación se presentaron manchas irregulares color marrón (Figura 6A). Posteriormente, a las 20 ddi la pudrición tomó una tonalidad marrónnegro con un hundimiento en el mismo. El avance del oscurecimiento de la lesión ocurrió del centro hacia los bordes del síntoma descrito (Figura 6B).
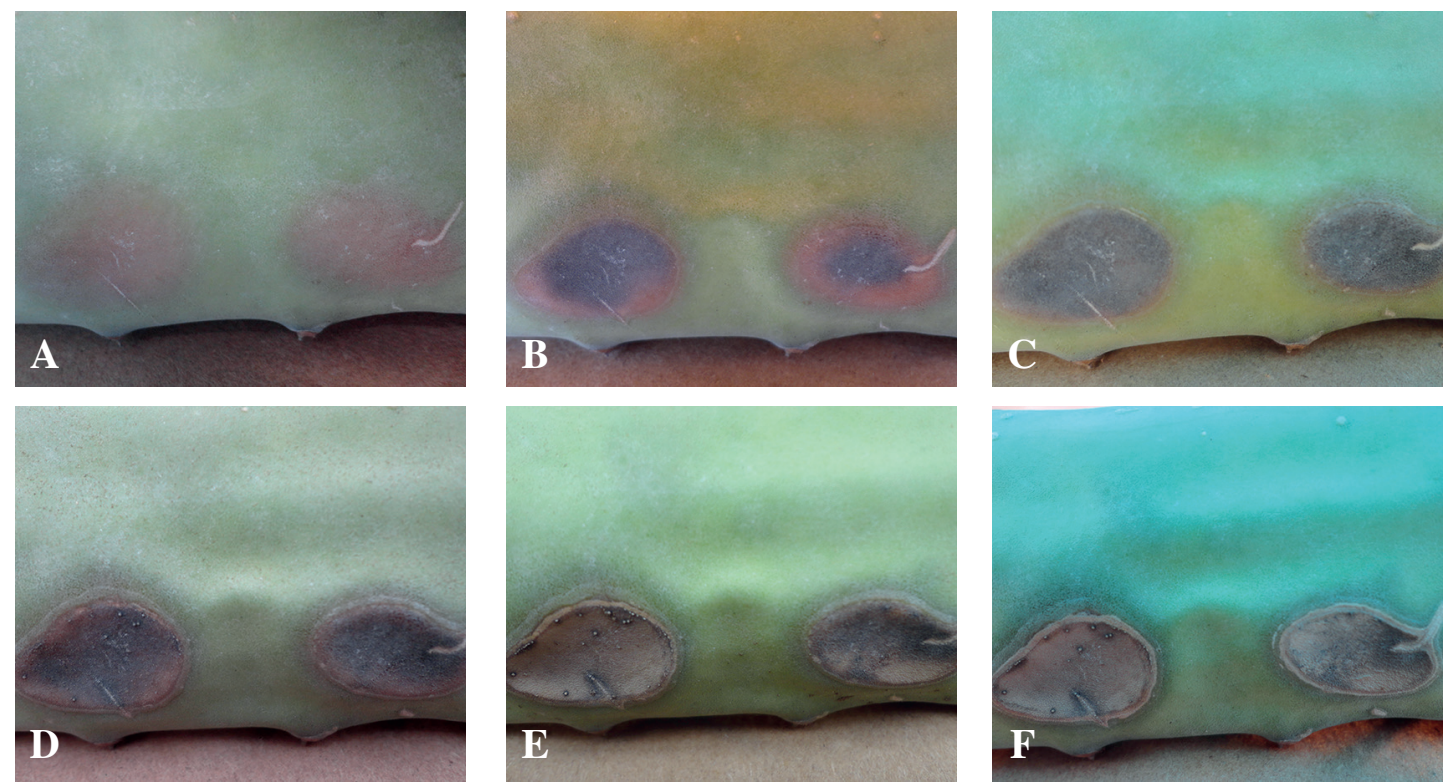

Fig. 6. Síntomas provocados por E. hormaechei inoculada en tallos sanos, en la cara opuesta de los puntos de inoculación. A. Día 8. B. Día 20. C. Día 24. D. Día 36. E. Día 44. F. Día 52; después de la inoculación.

A los 24 ddi, se dio la pudrición por completo del tejido infectado (Figura 6C). Doce días después, se presentó un aumento del hundimiento en las lesiones y el inicio de un cambio de color de marrón oscuro a marrón claro (Figura 6D), el cual se finalizó a los 44 ddi (Figura 6E).

Aproximadamente, 7 semanas después, se obtuvo como síntoma final lesiones blanquecinas irregulares blanquecinas con halo clorótico, sin la presencia de estructuras de organismos secundarios (Figura 6F). De los reaislamientos de los síntomas descritos se obtuvo la misma bacteria inoculada.

Esta bacteria se reporta como un organismo benéfico para las plantas, asociado al sistema radical de varios cultivos y relacionado con la promoción del crecimiento. A pesar de lo anterior y con base en observaciones de campo, 
se presume que la bacteria, además de aprovechar heridas para ingresar en los tejidos, puede ser endófita (se reporta como tal en otras especies vegetales) y se comporta como un organismo fitopatógeno cuando la planta se encuentra bajo condiciones de estrés (Kampfer et al. 2005, Ogbo y Okonkwo 2012, Ying et al. 2013, Egamberdieva et al. 2014).

Durante el desarrollo del estudio, se observó que en la época seca las plantas presentaron síntomas de estrés lumínico y a la vez un incremento de la incidencia y la severidad de la enfermedad causada por la bacteria. Esta situación se puede deber a que la pitahaya requiere de $30 \%$ a $60 \%$ de sombra, por lo que un un flujo de fotones para la fotosíntesis (FFF) mayor a $20 \mathrm{~mol} \mathrm{~m}^{-2}$ $\mathrm{d}^{-1}$ puede provocar fotoinhibición en especies como $H$. undatus. Lo anterior puede ocurrir en otras especies a diferentes FFF cercanos al valor mencionado, lo que se traduce en una menor tasa fotosintética y altera los recursos disponibles para la defensa de la planta (Raveh et al. 1998, Nobel y De la Barrera 2004).

Cabe señalar que la situación mencionada puede estar implícita en las diferencias de la sintomatología que se presenta en la época lluviosa y seca. Es decir, cambios en las condiciones ambientales y en la capacidad de respuesta de la planta pueden generar modificaciones en los síntomas que este patógeno provoca (Arauz 2011, Retana 2015).

El primer reporte científico de pudriciones provocadas por una enterobacteria en tallos de pitahaya fue realizado por Masyahit y colaboradores en el 2009, en plantaciones comerciales de esta fruta en Malasia. Este es el primer reporte que se hace en el continente americano de E. hormaechei como patógeno de Hylocereus costaricensis.

\section{LITERATURA CITADA}

Arauz, L. 2011. Fitopatología: un enfoque agroecológico. 2 ed. San Pedro, Costa Rica, Editorial de la Universidad de Costa Rica. 514 p.
Atlas, R. 2010. Handbook of microbiological media. Fourth Edition. Washington, USA, ASM Press-CRC Press. $2036 \mathrm{p}$.

Brenner, D; McWhorter, A; Kai, A; Steigerwalt, A; Farmer, J. 1986. Enterobacter asburiae sp. nov., a new species found in clinical specimens, and reassignment of Erwinia dissolvens and Erwinia nimipressuralis to the genus Enterobacter as Enterobacter dissolvens comb. nov. and Enterobacter nimipressuralis comb. nov. Journal of Clinical Microbiology 23(6):11141120.

Davin, A; Bosi, C; Charrel, R; Ageron, E; Papazian, L; Grimont, P, Cremieux, A; Bollet, A. 1997. A nosocomial outbreak due to Enterobacter cloacae strains with the $E$. hormaechei genotype in patients treated with fluoroquinolones. Journal Clinical Microbiology 35:1008-1010.

Egamberdieva, D; Botir, H; Abeer, H; Abd-Allah, E. 2014. Characterization of salt tolerant Enterobacter hormaechei strain associated with tomato root grown in arid saline soil. Journal of Pure and Applied Microbiology 8(5):4231-4239.

Faheed, F; Mazen, A; Abd Elmohsen, S. 2012. Physiological and ultrastructural studies on calcium oxalate crystal formation in some plants. Turkish Journal of Botany 37:139-152.

Franceschi, V; Horner, H. 1980. Calcium oxalate crystals in plants. Botanical Review 46(4):361-427.

French, E; Hebert, T. 1980. Métodos de investigación fitopatológica. San José, Costa Rica, Instituto Interamericano de Ciencias Agrícolas (IICA). 288 p.

Grimont, F; Grimont, P. 2006. The Genus Enterobacter. Prokaryotes 6:197-214.

Hall, T. 1999. BioEdit: A user-friendly biological sequences aligment editor and analysis program for Windows. Nucleic Acids Symposium Series 41:95-98.

Hoffmann, H; Roggenkamp, A. 2003. Population Genetics of the nomenspecies Enterobacter cloacae. Applied and Environmental Microbiology 69(9):5306-5318.

Hoffmann, H; Stindl, S; Ludwig, W; Stumpf, A; Mehlen, A; Heesemann, J; Monget, D; Schleifer, K; Roggenkamp, A. 2005. Reassignment of Enterobacter dissolvens to Enterobacter cloacae as E. cloacae subspecies dissolvens comb. nov. and emended description of Enterobacter asburiae and Enterobacter kobei. Systematic and Applied Microbiology 28:196-205.

Kampfer, P; Ruppel, S; Remus, R. 2005. Enterobacter radicincitans sp. nov., a plant growth promoting species of the family Enterobacteriaceae. Systematic and Applied Microbiology 28:213-221.

Lane, D; Pace, B; Olsen, G; Stahl, D; Sogin, M; Pace, N. 1985. Rapid determination of 16 S ribosomal RNA sequences for phylogenetic analyses. Proceedings of the National Academy of Sciences of the United States of America A82:6955-6959. 
Masratul, M; Baharuddin, S; Latiffah, Z. 2013. Identification and molecular characterizations of Neoscytalidium dimidiatum causing stem canker of red-fleshed dragon fruit (Hylocereus polyrhizus) in Malaysia. Journal of Phytopathology 161(11-12):841-849.

Masyahit, M; Sijam, K; Awang, Y; Ghazali, M. 2009. First report on bacterial soft rot disease on dragon Fruit (Hylocereus spp.) caused by Enterobacter cloacae in peninsular Malaysia. International Journal of Agriculture \& Biology 11:659-666.

Murray, M; Thompson, W. 1985. Rapid isolation of high molecular weight plant DNA. Nucleid Acids Research 8(19):4321-4325.

Neefs, J; Peer, I; De Rijk, P; Chapelle, S; De Wachter, R. 1993. Compilation of small ribosomal subunit RNA structures. Nucleic Acids Research 21(13):3025-3049.

Nobel, P; De La Barrera, E. 2004. $\mathrm{CO}_{2}$ uptake by the cultivated hemiepiphytic cactus, Hylocereus undatus. Annals of Applied Biology 144:1-8.

Ogbo, F; Okonkwo, J. 2012. Some characteristics of a plant growth promoting Enterobacter sp. isolated from the roots of maize. Scientific Research 2:368-374.

O'Hara, C; Steigerwal, A; Hill, B; Farmer, J; Fanning, G; Brenner, D. 1989. Enterobacter hormaechei, a new species of the family Enterobacteriaceae formerly known as enteric group 75. Journal of Clinical Microbiology 27(9):2046-2049.

OIRSA. 2000. Manual técnico: Buenas prácticas del cultivo de la pitahaya. Nicaragua, Proyecto Vifinex. $51 \mathrm{p}$.

Ortiz; Y; Carrillo, J. 2012. Pitahaya (Hylocereus spp.): a short review. Comunicata Scientiae 3(4):220-237.

Palmateer, A; Ploetz, R. 2007. First occurrence of anthracnose caused by Colletotrichum gloeosporioides on pitahaya. Plant Disease 91:631.

Pincus, D. 2005. Microbial identification using the Biomérieux Vitek® 2 System. In Miller, M (ed.). Encyclopedia of Rapid Microbiological Methods. Oklahoma, United States, Parenteral Drug Association and Davis Healthcare International Publishing. Vol. II. p. 1-32.

Puerta, A; Mateos, F. 2010. Enterobacterias. Medicine 10(51):3426-3431.

Raveh, E; Nerd, A; Mizrahi, Y. 1998. Responses of two hemiepiphytic fruit crop cacti to different degrees of shade. Scientia Horticulturae 73:151-164.

Retana, K. 2015. Diagnóstico y fluctuación estacional de las enfermedades presentes en el cultivo de la pitahaya (Hylocereus spp.) en Miramar, provincia de Puntarenas. Tesis M.Sc. San José, Costa Rica, Universidad de Costa Rica. 110 p.
Rodríguez, E; Gamboa, M; Hernández, F; García, J. 2005. Bacteriología general: principios y prácticas de laboratorio. San Pedro, Costa Rica, Editorial de la Universidad de Costa Rica. 475 p.

Schaad, N; Jones, J; Chun W. 2001. Laboratory guide for identification of plant bacteria. Third edition. The American Phytopathological Society. 373 p.

Stintzing, F; Schieber, A; Reinhold, C. 2001. Phytochemical and nutritional significance of cactus pear. European Food Research and Technology 212:396-407.

Stintzing, F; Schieber, A; Reinhold, C. 2002. Betacyanins in fruits from red-purple pitaya, Hylocereus polyrhizus (Weber) Britton \& Rose. Food Chemistry 77:101-106.

Strack, Z; Vogt, T; Schliemann, W. 2003. Recent advances in betalain research. Phytochemistry 62:247-269.

Tang, Y; Ellis, N; Hopkins, M; Smith, D; Dodge, D; Persing, D. 1998. Comparison of phenotypic and genotypic techniques for identification of unusual aerobic pathogenic Gram-negative bacilli. Journal of Clinical Microbiology 36(12):3674-3679.

Valencia, A; Cruz, P; Rodríguez, A. 2003. Avances en la etiología y manejo de la pudrición blanda de los tallos de pitahaya (Hylocereus undatus) Cactaceae. Revista Fitosanidad 7:11-17.

Valencia, A; Kokubu, H; Ruvalcaba, D. 2013. A brief overview on pitahaya (Hylocereus spp.) diseases. Journal of the Professional Association for Cactus Development 15:42-48.

Valencia, A; Sandoval, S; Cardenas, E. 2004. A new spot disease of pitahaya (Hylocereus undatus Haw. Britton and Rose) caused by Fusicococum.like anamorph of Botryosphaeria dothidea (Moug. Fr.) Ces. and De Not. in Mexico. Revista Mexicana de Fitopatología 22(1):140-142.

Webb, M. 1999. Cell-mediated crystallization of calcium oxalate in plants. The Plant Cell 11:751-761.

Wright, E; Rivera, M; Ghirlanda, A. 2007. Basal rot of Hylocereus undatus caused by Fusarium oxysporum in Buenos Aires. Plant Disease 91:323.

Wybraniec, S; Plazner, I; Geresh, S; Gotlieb, M; Haimberg, M; Mogilnitzki, M; Mizrahi, Y. 2001. Betacyanins from vine cactus Hylocereus polyrhizus. Phytochemistry 58:1208-1212.

Ying, C; Yin, Y; Rohani, R; Weber, J; Janardhan, S. 2013. Diversity of endophytic bacteria in Malaysian plants as revealed by $16 \mathrm{~S}$ rRNA encoding gene sequence based method of bacterial identification. Journal of Young Pharmacists 5:95-97. 
